\title{
Superselective Intra-Arterial Ethanol Sclerotherapy of Feeding Artery and Nidal Aneurysms in Ruptured Cerebral Arteriovenous Malformations
}

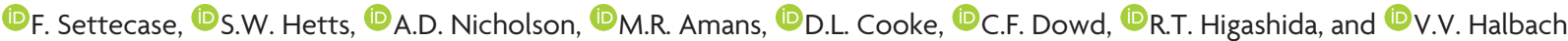

\begin{abstract}
SUMMARY: In the endovascular treatment of cerebral arteriovenous malformations, ethanol sclerotherapy is seldom used due to safety concerns. However, when limited reflux of an embolic agent is permissible or when there is a long distance to the target, ethanol may be preferable. We reviewed 10 patients with 14 cerebral AVM feeding artery aneurysms or intranidal aneurysms treated with intra-arterial ethanol sclerotherapy at our institution between 2005 and 2014. All patients presented with acute intracranial hemorrhage. Thirteen of 14 aneurysms were treated primarily with $60 \%-80 \%$ ethanol into the feeding artery. Complete target feeding artery and aneurysm occlusion was seen in all cases; 8/13 (62\%) were occluded by using ethanol alone. No retreatments or recurrences were seen. One permanent neurologic deficit $(1 / 13,7.7 \%)$ and no deaths occurred. In a subset of ruptured cerebral AVMs, ethanol sclerotherapy of feeding artery aneurysms and intranidal aneurysms can be performed with a high degree of technical success and a low rate of complication.
\end{abstract}

ABBREVIATIONS: FAA = feeding artery aneurysm; EtOH = ethanol; INA = intranidal aneurysm

A neurysms are often seen in association with cerebral arteriovenous malformations, occurring either along an artery supplying the AVM, within the AVM nidus, or arising from an unrelated artery. Flow-related feeding artery aneurysms and intranidal aneurysms are a primary source of hemorrhage in ruptured cerebral AVMs. ${ }^{1-3}$ Currently, treatment options for cerebral AVMs include surgery, stereotactic radiosurgery, and endovascular embolization, each of which may be performed as a stand-alone therapy or in combination. Embolization alone is rarely curative, and its primary role is to promote safer surgical resection by decreasing blood loss, shortening the length of surgery, reducing the risk of damage to surrounding structures, and increasing the likelihood of complete resection. Embolization may also render an AVM more amenable to radiosurgery by reducing the size of the AVM nidus and can be used to treat feeding artery or intranidal

Received June 25, 2015; accepted after revision August 10.

From the Division of Interventional Neuroradiology, Department of Radiology and Biomedical Imaging, University of California, San Francisco, San Francisco, California.

Paper previously presented at: Annual Meeting of the Society of Neurointerventional Surgery, July 27-30, 2015; San Francisco, California.

Please address correspondence to Fabio Settecase, MD, MSc, FRCPC, Division of Interventional Neuroradiology, Department of Radiology and Biomedical Imaging, University of California, San Francisco, 505 Parnassus Ave, L351, San Francisco, CA, 94143; e-mail: fabio.settecase@ucsf.edu

三 Indicates article with supplemental on-line table.

http://dx.doi.org/10.3174/ajnr.A4584 aneurysms, especially if deep-seated and difficult to access or control surgically. ${ }^{4-7}$

Embolization of an AVM requires superselective catheterization and distal placement of the microcatheter within a feeding artery, aiming to protect the parent artery from any reflux of embolic material and any en passage branches from nontarget embolization. The most commonly used embolic material is $n$-butyl cyanoacrylate, a quickly polymerizing liquid adhesive. Ethylene vinyl copolymer (Onyx; Covidien, Irvine, California $)^{8-10}$ is a newer but less commonly used embolic agent in AVM treatment. Particles ${ }^{11}$ and detachable coils are infrequently used.

Ethanol sclerotherapy is commonly used in the treatment of extracranial AVMs, ${ }^{12-15}$ yet it is seldom used in the treatment of cerebral AVMs due to safety concerns. ${ }^{16-25}$ In some circumstances, such as when distal microcatheter positioning beyond the proximal portion of a small feeding artery is not possible, however, the use of ethanol may be preferable. In this retrospective case series, we report our experience with patients whose brain AVMs presented with acute intracranial hemorrhage in whom ethanol sclerotherapy was preferable to other embolization techniques to treat feeding artery aneurysms (FAAs) or intranidal aneurysms (INAs).

\section{Case Series}

Under an institutional review board-approved protocol, a keyword search of the University of California, San Francisco neurointerventional data base identified 10 patients with cerebral 


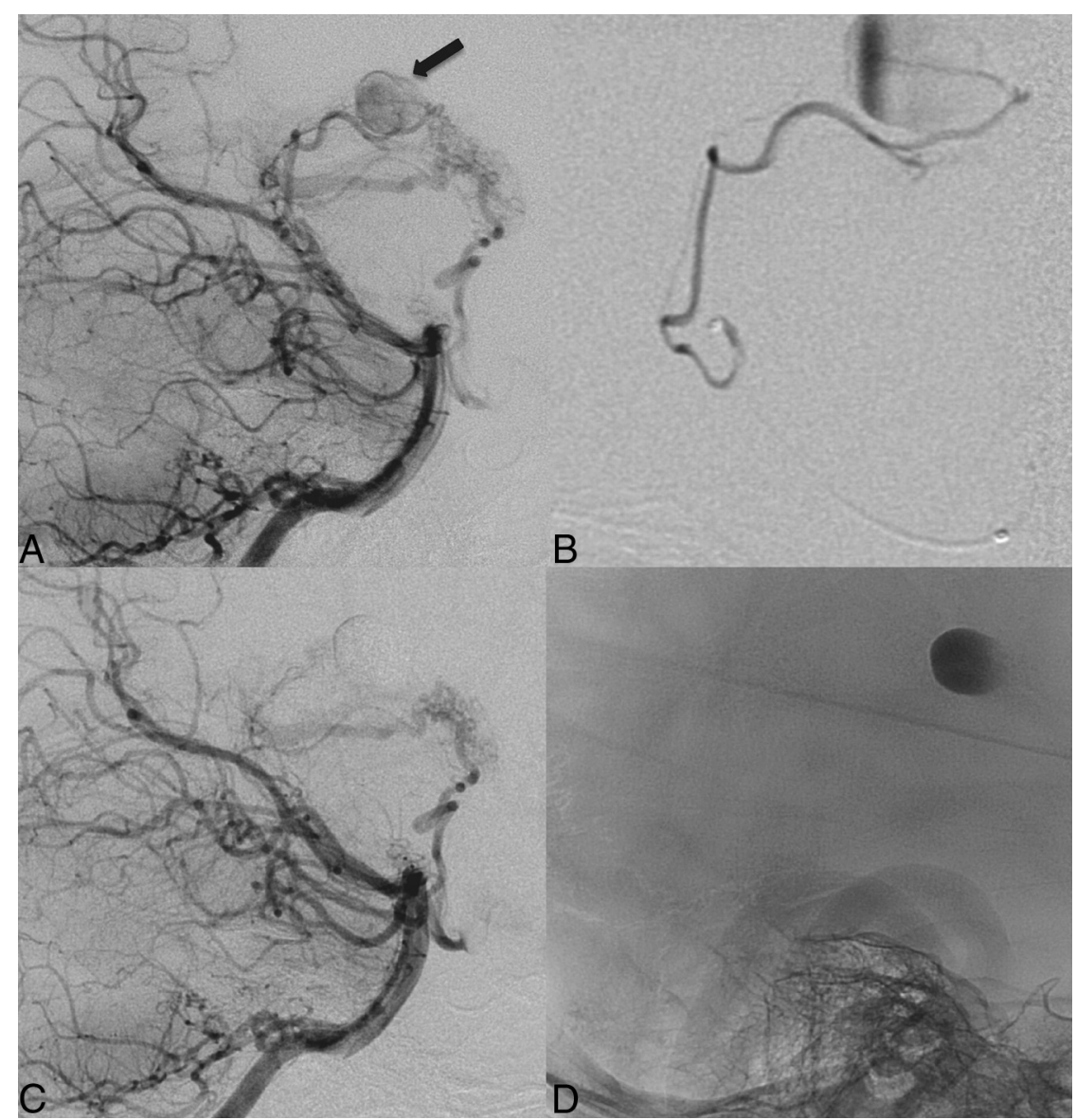

FIG 1. Ethanol sclerotherapy of a feeding artery aneurysm in a 5-year-old girl with a right thalamic AVM. A, Lateral view, left vertebral artery injection demonstrates an 11-mm feeding artery aneurysm (arrow) arising from the right posterolateral choroidal artery at the posterior aspect of the AVM nidus. B, Superselective microcatheter injection of the right posterolateral choroidal artery again demonstrates the feeding artery aneurysm. Note that the microcatheter is positioned in the proximal portion of right posterolateral choroidal artery. More distal catheterization of this artery was not possible. C, Lateral view left vertebral artery injection 20 minutes after intraarterial sclerotherapy with $5 \mathrm{~mL}$ of $70 \%$ ethanol demonstrates lack of filling of the feeding artery and aneurysm. $D$, Unsubtracted lateral view of the skull at the end of the sclerotherapy treatment demonstrates stasis of contrast within the aneurysm.

AVMs and associated FAAs or INAs treated by using super selective intra-arterial ethanol sclerotherapy between 2005 and 2014. Neuroimaging, angiograms, operative reports, and electronic medical records were reviewed for each patient by a boardcertified radiologist with a Certificate of Added Qualification in neuroradiology, 2 years' work experience in diagnostic neuroradiology, and additional training in interventional neuroradiology (F.S.).

After presentation with intracranial hemorrhage and CT and/or CT angiographic evidence of an underlying cerebral arteriovenous malformation, patients were referred to the interventional neuroradiology service for diagnostic cerebral angiography. Indications for AVM endovascular embolization were determined by clinical presentation, cross-sectional imaging, and angiographic findings. In all cases in this series, the decision to proceed with embolization was determined by the presence of intracranial hemorrhage in the setting of a cerebral AVM and the presence of either a FAA or INA suspected as the hemorrhage source and/or at risk for future hemorrhage (Figs 1 and 2). Indications for treatment and treatment strategy were agreed upon by the attending neuroradiologist (V.V.H.) and the admitting neurosurgeon in all cases. In all cases, the primary goal of treatment was obliteration of the FAA or INA. AVM nidus-size reduction or obliteration was a secondary goal. All patients consented to the use of a number of possible embolic materials as well as ethanol. The decision to use ethanol was made during the procedure, after obtaining superselective distal catheter positioning and on the basis of several factors, including the following: distance from the microcatheter tip to the target aneurysm, position of the catheter just beyond a branch point in which 1 branch was en passage to normal brain (eg, catheter positioned in the origin of the posterolateral choroidal artery), and amount of flow present within the feeding artery before treatment. For the concentration and volume of ethanol, we also took into account the above factors. In addition, serial angiograms were obtained midsclerotherapy to determine the efficacy of ethanol sclerotherapy and whether additional volume or change in the concentration of ethanol was necessary. In cases in which residual flow within the feeding artery and incomplete aneurysm occlusion were seen, adjunctive endovascular therapies were performed, such as coil placement or n-butyl cyanoacrylate embolization.

Noncontrast head CTs were reviewed to determine the presence and location of intracranial hemorrhage. Angiograms were reviewed to score the AVM grade and to determine the AVM location, the presence and number of feeding arteries or nidal aneurysms, the feeding artery from which the aneurysm arose, and the presence or absence of aneurysm filling on posttreatment runs. AVM size was estimated from MR imaging and angiography, and all AVMs were classified according to the Spetzler-Martin grading scale. ${ }^{26}$ The clinical status of patients was assessed at presentation, after embolization, and throughout hospitalization by members of the interventional neuroradiology and neurosurgical teams; and at follow-up visits by a neurosurgeon. Ethanol sclerotherapy was performed in all patients. Operative reports were reviewed to determine the aneurysm size, percentage of ethanol concentration used, amount of ethanol injected, adjunctive treatments, and periprocedural complications. The electronic medical record and follow-up digital subtraction angiograms were reviewed to determine the number of treatment sessions, aneurysm recurrence, delayed complications or death, definitive AVM treatments, and duration of follow-up. No clinical or angiographic follow-up was available in 1 patient. 


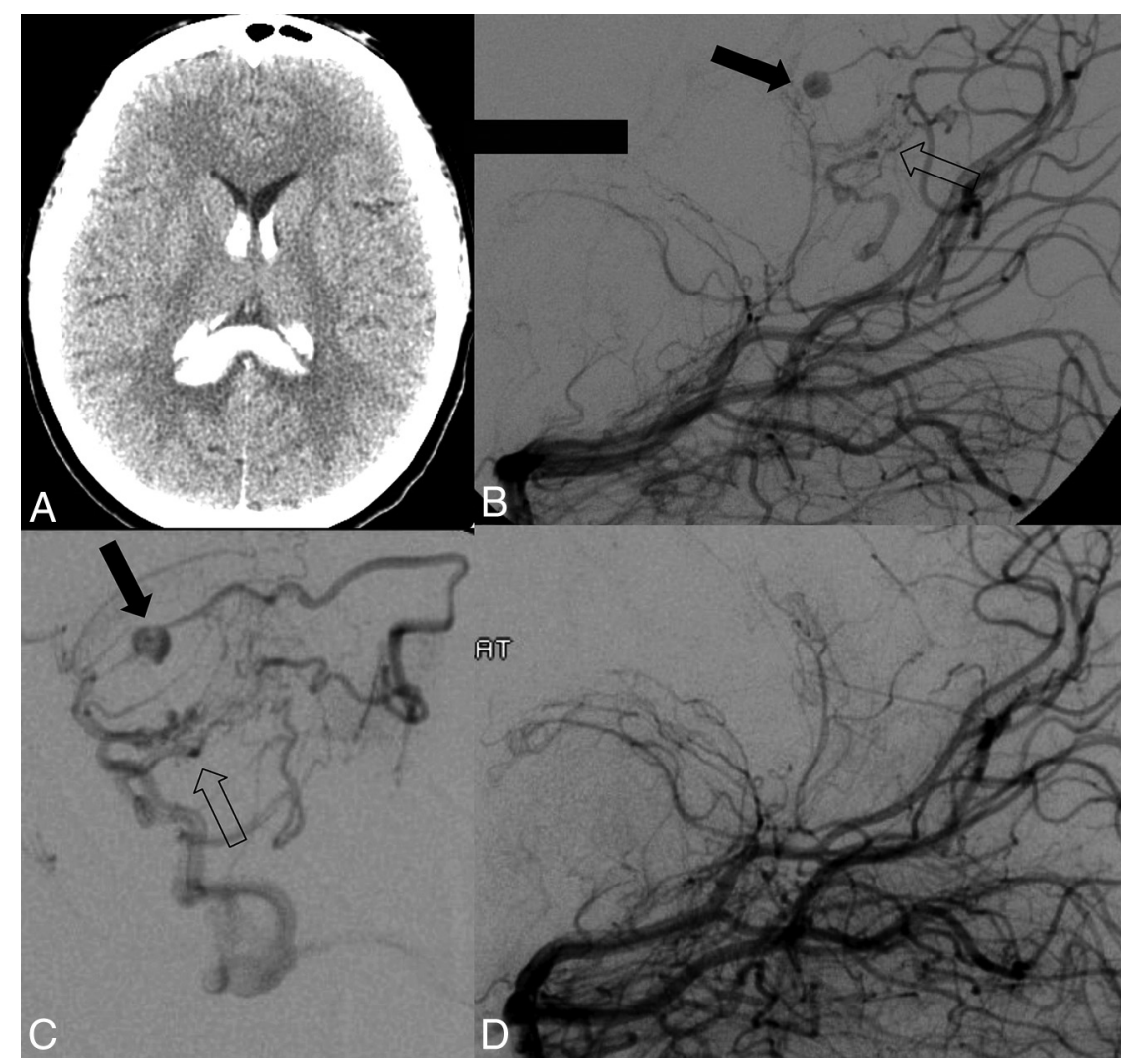

FIG 2. Ethanol sclerotherapy of a feeding artery aneurysm in a 15-year-old girl presenting with headache. A, Noncontrast CT head axial image demonstrates acute intraparenchymal hemorrhage centered in the splenium of the corpus callosum with intraventricular extension. $B$, Selective injection of the left vertebral artery in a reverse Schuller projection demonstrates a small AVM nidus (open arrow) and a 5-mm feeding artery aneurysm arising from the right splenial artery (black arrow). C, Lateral view of a superselective microcatheter injection of the right splenial artery. The AVM nidus (open arrow) and a 5-mm feeding artery aneurysm (black arrow) are again seen. $D$, Twenty minutes after ethanol sclerotherapy with $4 \mathrm{~mL}$ of $70 \%$ ethanol, posttherapy reverse Schuller projection of a left vertebral artery injection demonstrates the absence of the feeding artery aneurysm and AVM nidus and no evidence of arteriovenous shunting.

\section{Endovascular Procedure}

Informed consent was obtained from the patient or family before diagnostic angiography and possible endovascular therapy, including possible ethanol sclerotherapy. Potential risks discussed included those directly related to the procedure and those related to general anesthesia. All procedures were performed on a biplane angiographic unit with the patient under general anesthesia (with neuromuscular blockade administered and confirmed just before ethanol injection). Arterial lines were placed in each patient. Percutaneous vascular access was obtained through the right or left common femoral artery by using a standard coaxial technique. A complete cerebral angiogram that included both internal carotid arteries, the dominant vertebral artery, and, in some cases, the ipsilateral external carotid artery was obtained before treatment to identify the arterial feeders of the AVM. After a decision to treat was made and following any necessary upsizing of the vascular groin sheath, an intravenous bolus of $70 \mathrm{IU} / \mathrm{kg}$ body weight of heparin was administered and postheparin activated clotting time was obtained. A half dose of the initial bolus dose of IV heparin was administered at 1-hour intervals during the embolization procedure.

A guiding catheter was placed into the ipsilateral internal carotid artery or dominant vertebral artery; then, either a flowdirected microcatheter or an over-the-wire microcatheter was advanced under fluoroscopic and roadmap guidance into the AVM feeding artery branch. No provocative testing was performed. The microcatheter was positioned as distally as possible within the feeding artery to rest as close as possible to the AVM nidus or in a position for embolizing the feeding artery aneurysm while avoiding nontarget en passage branch embolization. Once an adequate microcatheter position was obtained, the microcatheter was flushed with $0.3-0.5 \mathrm{~mL}$ of heparinized normal saline. Dehydrated absolute ethanol was drawn into a 1-mL Luer lock syringe and mixed with varying amounts of heparinized iohexol contrast (Omnipaque 300; GE Healthcare, Piscataway, New Jersey) to achieve the desired final concentration of ethanol for sclerotherapy. Short, gentle pulsed injections of ethanol were performed via the microcatheter under roadmap blank fluoroscopic monitoring, aiming to avoid reflux. After delivery of 1-2 $\mathrm{mL}$ of the ethanol-contrast mixture, 10-20 minutes were allowed to elapse before performing a midembolization angiographic run through the microcatheter to allow ethanol to take effect on the arterial endothelium. Midsclerotherapy runs were then performed to determine whether any residual filling of the aneurysm or upstream feeding artery remained. In some cases, additional volumes of ethanol-contrast mixtures were administered and, after another 10- to 20-minute delay, angiography was repeated. If no further contrast filling of the aneurysm and upstream feeding artery was seen, no further sclerotherapy or adjunctive embolization was performed. In some cases, residual filling of the feeding artery and aneurysm was observed, and adjunctive therapies such as placement of detachable coils or injection of $n$-BCA was performed.

\section{Patients}

From 2005 to 2014, 10 patients with a ruptured cerebral AVMs and associated FAAs or INAs were treated at our hospital by using superselective intra-arterial ethanol sclerotherapy. There were 5 males and 5 females, with a mean age of $25 \pm 21$ years (median, 15 years; range, 1-64 years). All patients underwent CT, MR imaging, and digital subtraction angiography. Clinical presentation included intraventricular hemorrhage in all patients, intraparenchymal hemorrhage in $8 / 10$ patients, and subarachnoid hemorrhage in 4/10 patients. The AVM Spetzler-Martin grades ranged from II to IV (Table). Aneurysm sizes ranged from 1 to $11 \mathrm{~mm}$ (average size, $4 \pm 2.4 \mathrm{~mm}$ ). 
Patient demographics, AVM, and flow-related aneurysm characteristics

\begin{tabular}{|c|c|c|c|c|c|c|c|}
\hline Case No. & Age (yr) & AVM Grade & AVM Location & Bleed & $\begin{array}{l}\text { Aneurysm } \\
\text { Size }(\mathrm{mm})\end{array}$ & $\begin{array}{l}\text { Aneurysm } \\
\text { Type }\end{array}$ & $\begin{array}{c}\text { Feeding Artery } \\
\text { to Aneurysm }\end{array}$ \\
\hline 1 & 53 & IV & L frontoparietal & IVH/IPH & 3 & FAA & LPICh \\
\hline 2 & 15 & ॥ & R splenium of corpus callosum & IVH/IPH & 5 & FAA & R splenial \\
\hline 3 & 32 & III & L cerebellum & $\mathrm{IPH} / \mathrm{SAH}$ & 4 & INA & L SCA \\
\hline 4 & 5 & III & $\mathrm{R}$ thalamus & $\mathrm{IPH} / \mathrm{IVH} / \mathrm{SAH}$ & 11 & FAA & R PlCh \\
\hline 5 & 1 & III & $\mathrm{R}$ thalamus & $\mathrm{IPH} / \mathrm{IVH} / \mathrm{SAH}$ & 3 and 1 & FAA & R PmCh \\
\hline 6 & 13 & ॥ & L parieto-occipital & IPH/IVH & 3 and 2 & INA & LPO \\
\hline 7 & 11 & IV & $\mathrm{L}$ insula & $\mathrm{IPH} / \mathrm{IVH} / \mathrm{SAH}$ & 3 & INA & L PlCh \\
\hline 8 & 64 & $\|$ & $\mathrm{R}$ thalamus & $\mathrm{IVH}$ & 4 & FAA & $\mathrm{RPmCh}$ \\
\hline 9 & 42 & III & $L$ thalamus & IPH/IVH & 6 & FAA & $\mathrm{LACh}$ \\
\hline 10 & 17 & III & R splenium of corpus callosum & $\mathrm{IVH}$ & 4 and 3 & INA & $\mathrm{R}$ pericallosal \\
\hline
\end{tabular}

Note:-IVH indicates intraventricular hemorrhage; IPH, intraparenchymal hemorrhage; PICh, posterolateral choroidal artery; PO, parieto-occipital artery; PmCh, posteromedial choroidal artery; Ach, anterior choroidal artery; L, left; R, right; SCA, superior cerebellar artery.

\section{RESULTS}

Fourteen feeding artery or intranidal aneurysms were identified in 10 patients, of which, 13 were treated with superselective intra-arterial ethanol sclerotherapy (On-line Table). One of the 14 aneurysms was not treated due to its location (arising from the calcarine artery with several en passage branches). Mixtures of $60 \%-80 \%$ ethanol (70\% ethanol was used in $7 / 10$ patients) were delivered slowly under roadmap-mask guidance directly into the feeding artery supplying the aneurysm. Posttherapy angiography to assess aneurysm occlusion was performed 10-20 minutes after ethanol injection. The volume of ethanol injected ranged from 2 to $22 \mathrm{~mL}$ (median, $3.75 \mathrm{~mL}$ ) (Table). Complete occlusion of the aneurysm and upstream feeding artery was seen in 13/13 treated aneurysms (100\%) (Figs 1 and 2), with 8/13 (62\%) aneurysms occluded by using ethanol sclerotherapy alone. In addition, ethanol sclerotherapy alone achieved both aneurysm occlusion and angiographic cure of the AVM in 2 cases (On-line Table, Fig 2).

Adjunctive endovascular interventions were performed after ethanol sclerotherapy to treat 5/13 (38\%) aneurysms in 4 patients. After ethanol sclerotherapy of 4 aneurysms, markedly decreased but residual blood flow in the feeding artery remained on post-ethanol (EtOH) angiography. To promote complete thrombo-occlusion of the feeding artery, we placed detachable coils within the feeding artery in $4 / 5$ aneurysms from the same microcatheter tip location as in the $\mathrm{EtOH}$ injection. In another patient, after an injection of $5 \mathrm{~mL}$ of $60 \%$ ethanol and another $5 \mathrm{~mL}$ of $80 \%$ ethanol into the feeding artery, slowed but persistent flow within the feeding artery and FAA was seen postsclerotherapy. During the same treatment session, $0.3 \mathrm{~mL}$ of $20 \% n$-BCA was used to embolize the aneurysm, feeding artery, and AVM nidus with no residual AVM or aneurysm filling after $n$-BCA embolization.

Follow-up was available in $9 / 10$ patients, with a mean follow-up of 1.3 years (range, 3 months to 5 years). None of the treated aneurysms required $>1$ treatment session, and there were no recurrences. One complication related to ethanol sclerotherapy was encountered $(1 / 13,7.7 \%)$ : This patient developed transient hemiparesis and aphasia after injection of $6 \mathrm{~mL}$ of $70 \%$ ethanol into a posterolateral choroidal artery feeding artery with a 3-mm FAA in a Spetzler-Martin grade IV left frontoparietal AVM. At 5-year follow-up, the hemiparesis had nearly completely resolved with motor examination notable for $4+/ 5$ strength in the tibialis anterior. His aphasia had also improved; however, he exhibited hesitant speech with paraphasic errors. No deaths were attributed to ethanol sclerotherapy in both the periprocedural and follow-up periods.

\section{DISCUSSION}

Our experience by using ethanol sclerotherapy for feeding artery aneurysms and intranidal aneurysms in a subset of ruptured cerebral AVMs demonstrates that complete aneurysm and upstream feeding artery occlusion may be achieved in most cases $(62 \%)$ with ethanol alone. Ethanol is a potent sclerosant, is relatively inexpensive, and has a widespread commercial availability. The injection of small volumes of high concentrations of ethanol results in the dehydration, precipitation, sloughing, and denudation of the vascular endothelium. ${ }^{16,19,27,28}$ In the presence of blood, an acute thrombosis may be initiated, leading to permanent vascular closure. ${ }^{16,27}$

In 5/13 aneurysms, ethanol sclerotherapy markedly reduced blood flow within the feeding artery; however, slow contrast filling of the aneurysm persisted and adjunct endovascular therapy was necessary for complete occlusion of the aneurysm and feeding artery. Adjunctive therapies included placement of 2 detachable coils or a fibered coil into the feeding artery from the same microcatheter tip location as that used for the EtOH injection or $n$-BCA embolization of the feeding artery (On-line Table). No correlation was found between the need for adjunct endovascular therapy (ie, coils or $n$-BCA) and the size of the flowrelated aneurysm or AVM or ethanol concentration or volume. Because EtOH acts directly on endothelial cells, factors that decrease the amount of time the EtOH dwells in the artery and is in contact with endothelium, such as feeding artery diameter and rate of AV shunting, are more likely to result in incomplete occlusion with EtOH alone. Nonetheless, 1 embolization session was sufficient to obtain complete obliteration for all 13 aneurysms, and no recurrences were seen after a mean follow-up of 1.3 years.

In our study, 1 complication (1/13 treated aneurysms, $7.7 \%$ ) occurred after ethanol sclerotherapy of a posterolateral choroidal feeding artery to the AVM, with periatrial white matter low attenuation seen on postoperative CT, likely due to a combination of vasogenic and cytotoxic edema of nontarget brain tissue. No deaths were attributed to ethanol sclerotherapy. An initial report of ethanol sclerotherapy of cerebral 
AVMs by Yakes et al ${ }^{16}$ described permanent complications developing in 8 of 17 (47\%) patients, of which 3 were permanent $(18 \%)$ and $5(29 \%)$ were transient complications, and 2 deaths $(2 / 17,12 \%)$ occurring at 4 and 14 months after ethanol treatment due to subarachnoid hemorrhage. The very high complication rate reported in that study has limited the use of ethanol in the treatment of cerebral AVMs. Since the study of Yakes et $\mathrm{al},{ }^{16}$ there have been no other published reports of the use of ethanol sclerotherapy of cerebral AVMs. Ethanol sclerotherapy continues to be routinely used, however, in the treatment of peripheral AVMs. ${ }^{29}$

The results of this study differ from those of the study by Yakes et $\mathrm{al}^{16}$ in several ways: First, in our study, the primary goal of therapy in each patient was obliteration of the feeding artery aneurysm or intranidal aneurysm, whereas AVM nidus obliteration or reduction in size of the AVM nidus was the primary goal in the Yakes et $\mathrm{al}^{16}$ study. The average volume of ethanol used was, therefore, much lower in our study (ie, 2-22 mL; median, $3.75 \mathrm{~mL}$ versus $0.8-112 \mathrm{~mL}$ ); this difference may have contributed to a lower complication rate. Second, ethanol concentrations used in our study varied from $60 \%$ to $80 \%$, compared with $98 \%$ ethanol used in the prior study. Yakes et al stated that nonionic contrast medium can be mixed with ethanol and precipitation does not occur; however, contrast media dilute ethanol to a level that renders it ineffective in achieving a sclerosing effect and thrombosis. In contrast, this study indicates that concentrations of $60 \%-80 \%$ ethanol have a potent sclerosing effect. Third, the presenting symptoms in our study were also different, with all AVMs in our study presenting with intracranial hemorrhage, whereas presentation varied in the prior study (hemorrhage in $7 / 17$ patients, seizures, hemianopsia, headaches, trigeminal neuralgia, and thalamic syndrome).

Despite the encouraging results of intra-arterial ethanol sclerotherapy demonstrated in this study in the setting of flow-related aneurysms in ruptured AVMs, we do not recommend routine use of this agent in the endovascular treatment of AVMs. Embolic materials such as $n$-BCA or Onyx remain first-line agents in the endovascular treatment of AVMs in our practice. In each case within this series, the choice of embolic agent versus sclerosant was not made a priori, rather only after superselective microcatheterization and distal access (or attempted distal access) of the feeding artery. The cases included in this series demonstrate that there are rare circumstances in which ethanol may be preferable to embolic agents - for example, when superselective catheterization, which minimizes the risk of reflux and nontarget embolization, is not possible, such as with an inability to position a microcatheter beyond the proximal portion of a small feeding artery (Fig 1; cases 1, 2, 4, 7, and 8). While reflux of an embolic agent into the parent artery in this situation could have devastating consequences, the risk of nontarget vascular injury from reflux of ethanol from the same vessel is decreased because ethanol concentration drops in the parent artery via dilution. A second scenario in which ethanol was preferable to embolic agents occurred when a particularly long distance between the microcatheter tip and the target aneurysm existed and there was substantial risk of a standard liquid embolic agent not reaching the target (cases 1-5, $7-10$ ). Consideration should also be given to the surgical ac- cessibility of FAA or INA if endovascular therapy is being performed preoperatively. The AVM itself or many of the FAAs/ INAs in this case series were deep-seated; this location favored endovascular over surgical treatment of the flow-related aneurysms. Careful consideration of the indications for treatment, efficacy, and risks of embolization materials ( $n$-BCA and Onyx) and ethanol must be made before treatment and once the final microcatheter position in the feeding artery is attained.

Extreme caution should be used when injecting ethanol in any concentration or amount due to the high toxicity of ethanol. Nontarget necrosis of adjacent tissues may occur with overinjection, localized extravasation, or reflux. ${ }^{16,20}$ In addition, ethanol may exert effects distant from the target site, including the venous system causing a thrombophlebitis; or (in larger quantities) more distant effects of intoxication, hemoglobinuria, pulmonary artery hypertension, pulmonary embolus, bronchospasm, hyperthermia, cardiopulmonary collapse, and death. ${ }^{16,18-25}$ Ethanol sclerotherapy has also been associated with disruption in coagulation profiles as evidenced by a decrease in platelets and fibrinogen, an increase in prothrombin time, and a conversion from negative to positive $\mathrm{D}$-dimers. ${ }^{30}$ In 1 case report, the bispectral index, a measure of the depth of anesthesia, fell to zero during ethanol sclerotherapy of a cerebral AVM. ${ }^{31}$ Therefore, great care should be taken to not exceed a per-procedure administered dose of $>1$ $\mathrm{mL} / \mathrm{kg} .{ }^{27}$ This study shows that volumes well below this threshold are efficacious (Table); however, close patient monitoring for the above adverse events and complications following ethanol sclerotherapy should always be performed.

In addition to the above effects, our group has also reported intraventricular contrast medium leakage mimicking intraventricular hemorrhage during intra-arterial 100\% ethanol sclerotherapy into the posterolateral choroidal artery in a 5-year-old child with a ruptured AVM. ${ }^{32}$ While such a phenomenon is uncommon and not reported elsewhere, the neurointerventionalist should be aware of it, especially because many of the feeding arteries in this study involved arteries supplying the choroid plexus.

This study has several important limitations. The retrospective nature limits the generalizability of the results, and a selection bias may be present. In addition, there was no comparison group to determine whether ethanol sclerotherapy would achieve better results with similar or fewer complications in similar cases with the use of other embolic materials, such as $n$-BCA or Onyx. Selection of a comparison group of flow-related aneurysms for this series would be difficult and impractical, however, because the catheter positions in which ethanol was used in nearly all patients in this cases series precluded the safe or efficacious use of embolic agents. The authors recommend against a study that compares the efficacy and safety profile of ethanol sclerotherapy with embolic agents in the setting of endovascular AVM treatment. ${ }^{16}$ In addition, because this study included only patients with ruptured AVMs, the results cannot be generalized to unruptured cerebral AVMs. Given the small number of patients in this study, results should be confirmed in a larger prospective study. Gross pathology confirmation of aneurysm obliteration was not possible in this study, and evidence of obliteration is based solely on follow-up conventional angiography in 9/10 patients. 
In conclusion, this study suggests that in a subset of ruptured cerebral AVMs, ethanol sclerotherapy of FAAs and INAs can be performed with a high degree of technical success and a low rate of complications.

Disclosures: Christopher F. Dowd—UNRELATED: Other: MicroVention, ${ }^{\star}$ Comments: Chief Adjudicator, Flow Redirection Intraluminal Device (FRED) Trial. *Money paid to the institution.

\section{REFERENCES}

1. Perata HJ, Tomsick TA, Tew JM Jr. Feeding artery pedicle aneurysms: association with parenchymal hemorrhage and arteriovenous malformation in the brain. J Neurosurg 1994;80:631-34 CrossRef Medline

2. Redekop G, TerBrugge K, Montanera W, et al. Arterial aneurysms associated with cerebral arteriovenous malformations: classification, incidence, and risk of hemorrhage. J Neurosurg 1998;89: 539-46 CrossRef Medline

3. Pollock BE, Flickinger JC, Lunsford LD, et al. Factors that predict the bleeding risk of cerebral arteriovenous malformations. Stroke 1996; 27:1-6 CrossRef Medline

4. Spetzler RF, Martin NA, Carter LP, et al. Surgical management of large AVM's by staged embolization and operative excision. $\mathrm{J} \mathrm{Neu}$ rosurg 1987;67:17-28 CrossRef Medline

5. Gobin YP, Laurent A, Merienne L, et al. Treatment of brain arteriovenous malformations by embolization and radiosurgery. J Neurosurg 1996;85:19-28 CrossRef Medline

6. Henkes H, Nahser HC, Berg-Dammer E, et al. Endovascular therapy of brain AVMs prior to radiosurgery. Neurol Res 1998;20:479-92 Medline

7. Richling B, Killer M. Endovascular management of patients with cerebral arteriovenous malformations. Neurosurg Clin N Am 2000; 11:123-45, ix Medline

8. Jahan R, Murayama Y, Gobin YP, et al. Embolization of arteriovenous malformations with Onyx: clinicopathological experience in 23 patients. Neurosurgery 2001;48:984-95; discussion 995-987 CrossRef Medline

9. Pierot L, Januel AC, Herbreteau D, et al. Endovascular treatment of brain arteriovenous malformations using Onyx: preliminary results of a prospective multicenter study. Interv Neuroradiol 2005;11: 159-64 Medline

10. van Rooij WJ, Sluzewski M, Beute GN. Brain AVM embolization with Onyx. AJNR Am J Neuroradiol 2007;28:172-77; discussion 178 Medline

11. Sorimachi T, Koike T, Takeuchi S, et al. Embolization of cerebral arteriovenous malformations achieved with polyvinyl alcohol particles: angiographic reappearance and complications. AJNR Am J Neuroradiol 1999;20:1323-28 Medline

12. Yakes WF. Endovascular management of high-flow arteriovenous malformations. Semin Intervent Radiol 2004;21:49-58 CrossRef Medline

13. Pekkola J, Lappalainen K, Vuola $\mathrm{P}$, et al. Head and neck arteriovenous malformations: results of ethanol sclerotherapy. AJNR AmJ Neuroradiol 2013;34:198-204 CrossRef Medline

14. Vogelzang RL, Atassi R, Vouche M, et al. Ethanol embolotherapy of vascular malformations: clinical outcomes at a single center. J Vasc Interv Radiol 2014;25:206-13; quiz 214 CrossRef Medline

15. Lee BB, Do YS, Yakes W, et al. Management of arteriovenous malformations: a multidisciplinary approach. J Vasc Surg 2004;39: 590-600 CrossRef Medline

16. Yakes WF, Krauth L, Ecklund J, et al. Ethanol endovascular management of brain arteriovenous malformations: initial results. Neurosurgery 1997;40:1145-52; discussion 1152-1144 CrossRef Medline

17. Wong GA, Armstrong DC, Robertson JM. Cardiovascular collapse during ethanol sclerotherapy in a pediatric patient. Paediatr Anaesth 2006;16:343-46 CrossRef Medline

18. Do YS, Yakes WF, Shin SW, et al. Ethanol embolization of arteriovenous malformations: interim results. Radiology 2005;235:674-82 CrossRef Medline

19. Shin BS, Do YS, Lee BB, et al. Multistage ethanol sclerotherapy of soft-tissue arteriovenous malformations: effect on pulmonary arterial pressure. Radiology 2005;235:1072-77 CrossRef Medline

20. Choi $\mathrm{YH}, \mathrm{Han} \mathrm{MH}, \mathrm{O}-\mathrm{Ki} \mathrm{K}$, et al. Craniofacial cavernous venous malformations: percutaneous sclerotherapy with use of ethanolamine oleate. J Vasc Interv Radiol 2002;13:475-82 CrossRef Medline

21. de Lorimier AA. Sclerotherapy for venous malformations. J Pediatr Surg 1995;30:188-93; discussion 194 CrossRef Medline

22. Behnia R. Systemic effects of absolute alcohol embolization in a patient with a congenital arteriovenous malformation of the lower extremity. Anesth Analg 1995;80:415-17 CrossRef Medline

23. Garel L, Mareschal JL, Gagnadoux MF, et al. Fatal outcome after ethanol renal ablation in child with end-stage kidneys. AJR Am J Roentgenol 1986;146:593-94 CrossRef Medline

24. Mason KP, Michna E, Zurakowski D, et al. Serum ethanol levels in children and adults after ethanol embolization or sclerotherapy for vascular anomalies. Radiology 2000;217:127-32 CrossRef Medline

25. Stefanutto TB, Halbach V. Bronchospasm precipitated by ethanol injection in arteriovenous malformation. AJNR Am J Neuroradiol 2003;24:2050-51 Medline

26. Spetzler RF, Martin NA. A proposed grading system for arteriovenous malformations. J Neurosurg 1986;65:476-83 CrossRef Medline

27. Yakes WF, Rossi P, Odink H. How I do it: arteriovenous malformation management. Cardiovasc Intervent Radiol 1996;19:65-71 CrossRef Medline

28. Yakes WF, Haas DK, Parker SH, et al. Symptomatic vascular malformations: ethanol embolotherapy. Radiology 1989;170: 1059-66 CrossRef Medline

29. Legiehn GM, Heran MK. A step-by-step practical approach to imaging diagnosis and interventional radiologic therapy in vascular malformations. Semin Intervent Radiol 2010;27:209-31 CrossRef Medline

30. Mason KP, Neufeld EJ, Karian VE, et al. Coagulation abnormalities in pediatric and adult patients after sclerotherapy or embolization of vascular anomalies. AJR Am J Roentgenol 2001;177:1359-63 CrossRef Medline

31. Unnikrishnan KP, Sinha PK, Sriganesh K, et al. Case report: alterations in bispectral index following absolute alcohol embolization in a patient with intracranial arteriovenous malformation. Can J Anaesth 2007;54:908-11 CrossRef Medline

32. Phatouros CC, Halbach VV, Malek AM, et al. Intraventricular contrast medium leakage during ethanol embolization of an arteriovenous malformation. AJNR Am J Neuroradiol 1999;20:1329-32 Medline 